\title{
Synthesis and preliminary evaluation of poly(amidoamine)- melittin conjugates as endosomolytic polymers and/or potential anticancer therapeutics
}

\author{
Nathalie Lavignac ${ }^{\mathrm{a}}$, Michelle Lazenby ${ }^{\mathrm{a}}$, Jacopo Franchini ${ }^{\mathrm{b}}$, \\ Paolo Ferruti ${ }^{b}$, Ruth Duncan ${ }^{\mathrm{a}, *}$ \\ a Centre for Polymer Therapeutics, Welsh, School of Pharmacy Redwood Building, Cardiff University, \\ King Edward VII Avenue, Cardiff CF10 3XF, UK \\ ${ }^{\mathrm{b}}$ Dipartimento di Chimica Organica e Industriale and Centro Interdisciplinare Materiali Innovativi Nanostrutturati (CIMAINA), \\ Università di Milano, Via Venezian 21, 20133 Milano, Italy
}

Accepted 2 June 2005

Available online 11 July 2005

\begin{abstract}
The pH-responsive poly(amidoamine)s (PAAs) have been previously described. Whereas ISA23 enhances transfection in vitro and ISA1 promotes the cytosolic delivery of the non-permeant toxins this process shows poor efficiency. The aim of this study was to prepare and evaluate PAA conjugates containing the membrane disrupting peptide melittin (MLT). It was hypothesised that PAA conjugation would reduce the haemolytic activity of MLT at $\mathrm{pH} 7.4$, however, upon delivery to tumours by the EPR effect, the polymer would uncoil in an acidic environment exposing MLT and allowing it to interact with membranes. PAA-MLT conjugates were prepared using MLT as a comonomer together with bis-acryloylpiperazine, 2-methylpiperazine and bis-hydroxyethylethylenediamine (ISA1-like), or bis-acrylamidoacetic acid and 2-methylpiperazine (ISA23-like). The melittin content of the conjugates was 6-19\% (w/w). Although ISA1-MLT improved gelonin delivery compared to the parent polymer ISA1 ( $\alpha 13$-fold increase) and showed $\mathrm{pH}$-dependent haemolytic activity at a polymer concentration of $0.05 \mathrm{mg} / \mathrm{ml}$, this conjugate also displayed high haemolytic activity at $\mathrm{pH}$ 7.4. In contrast, ISA23-MLT like the parent compound ISA23 did not deliver gelonin. However, this conjugate could have potential as a novel polymeric anticancer conjugate due to its lack of haemolytic activity at $\mathrm{pH} 7.4$ and retention of cytotoxicity.
\end{abstract}

(C) 2005 Elsevier B.V. All rights reserved.

Keywords: Endosomotropic delivery; pH-sensitive Polymers; Poly(amidoamine)s; Melittin

\section{Introduction}

* Corresponding author. Tel.: +44 2920874 180; fax: +442920 874536 .

E-mail address: duncanr@cf.ac.uk (R. Duncan).
Progress in genomics and proteomics research is leading to a better understanding of the molecular basis 
of many diseases. This, in turn, has generated increased interest in macromolecular therapeutics such as peptides, proteins and genes. Compared to low molecular weight new chemical entities these macromolecular drugs often present specific drug delivery challenges, not least their relative inability to access the intracellular compartments where many must interact with their pharmacological target (reviewed in Duncan, in press). Various approaches have been investigated as tools to improve cytosolic delivery. These include both natural (e.g. viruses) and synthetic non-viral vectors. The latter comprise cationic lipids, cationic polymers, e.g. polyethyleneimine (PEI) and poly(L-lysine) (PLL) (Wagner, 2004), and multicomponent systems sometimes including targeting ligands and membrane-active peptides (Wagner, 1999).

Due to the highly toxic nature of many cationic vectors we have been developing amphoteric poly(amidoamine)s (PAAs) as endosomolytic polymers to aid cytosolic entry of proteins and genes. These water soluble, biodegradable polymers are $>100$-fold less toxic than PEI and PLL (Richardson et al., 1999; Ferruti et al., 2000; reviewed in Ferruti et al., 2002). PAAs undergo a conformational change during progression from neutral to acidic $\mathrm{pH}$. The relatively coiled closed PAA structure at $\mathrm{pH} 7.4$ opens to a more extended (hydrophilic) structure as $\mathrm{pH}$ decreases. Recent studies using small angle neutron scattering (SANS) have shown that closed PAA coil $(\sim 2 \mathrm{~nm}$ in diameter) opens to a maximum of $\sim 8 \mathrm{~nm}$ (Griffiths et al., 2004). Studies examining the $\mathrm{pH}$-dependent haemolytic activity of a PAA-Triton X-100 construct showed the ability of the PAA backbone to shield a membrane active agent at neutral $\mathrm{pH}$, but expose it as $\mathrm{pH}$ decreased giving confidence that such polymers could be used as bioresponsive polymers able to promote endosomotropic delivery (Duncan et al., 1994). Recent experiments have also shown that choice of PAA counterion is critically important in determining effective membrane perturbation (Wan et al., 2004).

Two PAA structures have emerged as particularly interesting. An amphoteric PAA (ISA23) which is not

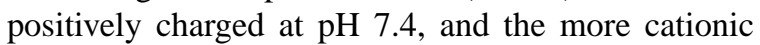
PAA ISA1 (Fig. 1). Whilst ISA23 showed greatest ability to act as a transfection reagent (Richardson et al., 2001), ISA1 (and not ISA23) was also able to deliver the non-permeant toxins gelonin and ricin (a)<smiles>CCC1CCCCC1CO</smiles><smiles>CCC(N1CCN(CCC(=O)N2CCN(C(=O)CC(C)(CC)CC)CC2)CC1)C(C)(CC)CC(=O)N1CC=CC1</smiles>

(b)

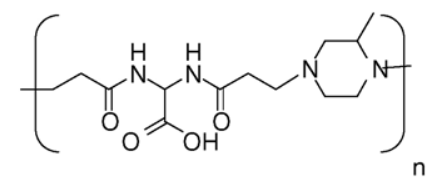

Fig. 1. Structure of poly(aminoamide)s. Panel (a) ISA1 and panel (b) ISA23.

A chain (RTA) (Pattrick et al., 2001). Although the latter observations were very promising, the molecular ratio of PAA:RTA needed to achieve the same toxicity as one molecule of ricin holotoxin was very high, i.e. $\sim 12,000: 1$. This prompted the search for PAA constructs with higher delivery efficiency. One recent approach was synthesis of random and block copolymers combining ISA1 and ISA23. However, only the block copolymer ISA23:ISA1 (molar ratio 2:1) was able to promote intracellular toxin delivery (Lavignac et al., 2004). Thus, having shown previously that melittin (MLT) conjugation to HPMA copolymers reduces non-specific haemolytic activity, the aim of this study was to investigate whether incorporation of MLT into PAA constructs would potentate endsomolytic efficiency whilst generating conjugates suitable for intravenous (i.v.) administration. MLT is a 26 amino acids peptide of $\alpha$-helical conformation and it is the main constituent of the venom of the European honey bee (Apis meliffera) (Dempsey, 1990) (Fig. 2). We hypothesised that incorporation of MLT to the PAA structure might produce a construct that could "shield" the peptide and reduce its haemolytic activity at $\mathrm{pH}$ 7.4. However, as it has been shown that PAAs can target tumours by the enhanced permeability and retention (EPR) effect (Matsumura and Maeda, 1986; Richardson et al., 1999), it might be predicted that the polymer would uncoil in an acidic environment (tumour interstitium or intracellular endosomal compartments) thus exposing MLT and allowing it to interact with membranes. Here we report the synthesis, characterisation and in vitro biological evaluation of PAA-MLT conjugates. 
$\mathrm{NH}_{2}$-Gly-Ile-Gly-Ala-Val-Leu-Lys -Val-Leu-Thr-Thr-Gly-Leu-Pro-Ala-Leu-

(a)

(b)

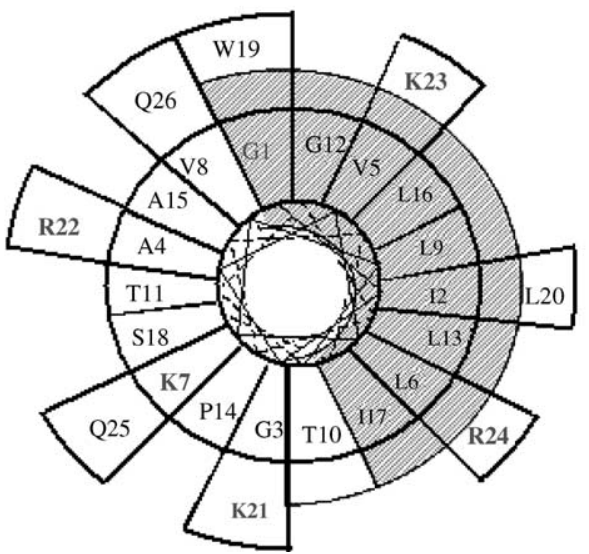

Fig. 2. The amino acid sequence of melittin (panel (a)) and its $\alpha$-helical wheel diagram, panel (b). The potentially charge-carrying amino acids are shown in bold and the hydrophobic segment is shaded.

\section{Materials and methods}

\subsection{Materials and equipment}

Sodium hydrogen carbonate $\left(\mathrm{NaHCO}_{3}\right)$, concentrated $\mathrm{HCl}$ and bis-hydroxyethylethylenediamine (DHE) were purchased from Fluka (Dorset, UK) and used without purification. 2-Methylpiperazine (2MePip) was also obtained from Fluka, but was recrystallised from $n$-hexane, its purity was determined titrimetrically before use. The monomers 2,2-bis-(acrylamido)acetic acid (BAC) and bis-acryloylpiperazine (BP) were synthesised as previously described (Ferruti, 1985) and their purity was determined titrimetrically (BAC) or by NMR (BP) just before use. Dextran $(\mathrm{Mw}=74,000 \mathrm{~g} / \mathrm{mol})$, gelonin, MLT, bovine serum albumin (BSA), 5-dimethylthiazol-2-yl-2,5diphenyltetrazolium bromide (MTT) and Triton X100 were all from Sigma (Dorset, UK) and were of analytical grade. PBS was supplied from Oxoid Ltd. (Basingstoke, UK). RPMI 1640 medium (25 mM HEPES) supplemented with L-glutamine, foetal bovine serum (FBS) and $0.25 \%$ trypsin-EDTA were purchased from Gibco-BRL (Paisley, UK). The B16F10 mouse melanoma cells were from ATCC (CRL-6475). ${ }^{1} \mathrm{H}$ NMR spectra were obtained in deuterated water on a Bruker $400 \mathrm{MHz}$ instrument.

\subsection{Synthesis and characterisation of PAAs and PAA-melittin conjugates}

Synthesis of PAAs by hydrogen-transfer polyaddition of primary amines to bis-acrylamide has been well documented (Ferruti et al., 1973, 2002; Ferruti, 1996). The parent polymers ISA1 and ISA23 were synthesised and characterised by ${ }^{1} \mathrm{H}$ NMR as described previously (Richardson et al., 1999; Ferruti et al., 2000). PAA-MLT conjugates were prepared using a two-step reaction involving an activated MLT comonomer (Schemes 1 and 2). In the first step, MLT was left to react for $1 \mathrm{~h}$ with bis-acrylamide to form an "activated trimer" bearing two terminal double bonds (Schemes 1a and 2a). This trimer was further used as comonomer in the final step of the copolymerisation (Schemes $1 b$ and $2 b$ ). After completion of the reaction, the conjugates were isolated as chloride salts, purified by ultrafiltration and lyophilised. Details of typical syntheses are given below.

As the $\mathrm{p} K_{\mathrm{a}}$ of the terminal MLT amino group is 7.8, and the $\mathrm{p} K_{\mathrm{a}}$ of lysine is 9.3-9.5 and arginine $>12$, under the reaction conditions used here only the terminal amino group would be protonated and this is therefore expected to be the only one to react. 


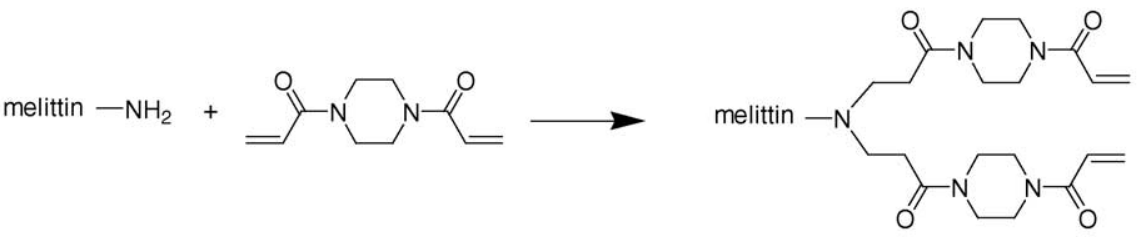

Step 1: Activation of melittin<smiles>C=CC(=O)N1CCN(C(=O)CCN(CCC(=O)N2CCNCC2)CCC(=O)N2CCN(C(=O)C=C)CC2)CC1</smiles>

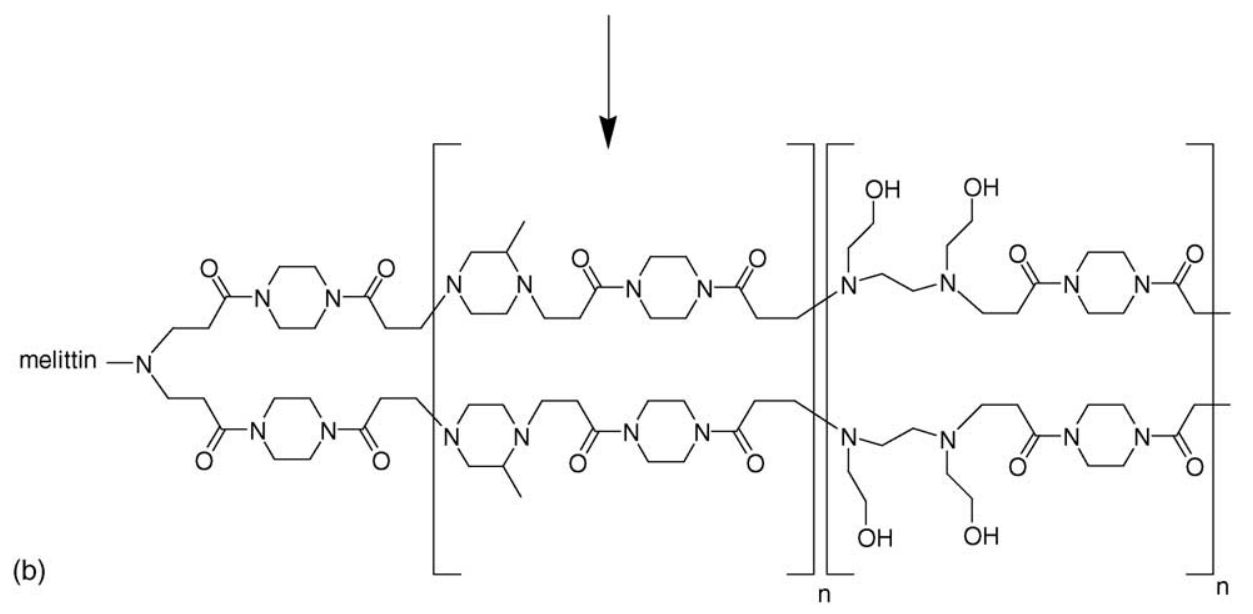

Step 2: Copolymerisation of activated melittin

Scheme 1. Synthesis of the melittin-ISA1-like conjugate.

\subsubsection{Synthesis of ISA1-MLT}

MLT (15 mg; $5.3 \mu \mathrm{mol})$ was dissolved in double distilled water $\left(\mathrm{ddH}_{2} \mathrm{O}, 424 \mu \mathrm{L}\right)$ and $\mathrm{BP}(35.9 \mathrm{mg}$; $185 \mathrm{mmol}$ ) was added under nitrogen $\left(\mathrm{N}_{2}\right)$. The mixture was stirred in the dark for $1 \mathrm{~h}$. Then MePip (9.5 mg; $92.5 \mathrm{mmol})$ and DHE (14.4 mg; $92.5 \mathrm{mmol})$ were added. The reaction was stirred under $\mathrm{N}_{2}$ and in the dark for 3 days. After diluting with $\mathrm{dd}_{2} \mathrm{O}$ and addition of $\mathrm{HCl}(5 \mathrm{M})$ until $\mathrm{pH} 2.5$ was reached, the solution was ultrafiltered using a membrane with a $\mathrm{Mw}=10 \mathrm{kDa}$ cut-off. The conjugate was recovered by freeze drying with a $75 \%$ yield.

\subsubsection{Synthesis of ISA23-MLT}

BAC (39.6 mg; $198 \mathrm{mmole}$ ) and $\mathrm{LiOH}(8.4 \mathrm{mg}$; $198 \mathrm{mmol})$ were dissolved in $\mathrm{ddH}_{2} \mathrm{O}(472 \mu \mathrm{L})$. MLT $(15 \mathrm{mg} ; 5.3 \mu \mathrm{mol})$ was added under $\mathrm{N}_{2}$. The mixture was stirred in the dark for $20 \mathrm{~min}$. Then MePip (20.4 mg; $198 \mathrm{mmol}$ ) was added and the reaction was stirred for 3 days. The ISA23-MLT conjugate was recovered as described above with a yield of $70 \%$.

\subsubsection{Characterisation of the melittin conjugates}

Molecular weight and polydispersity of the resultant conjugates was determined by gel permeation 
Scheme 2 Lavignac et al.

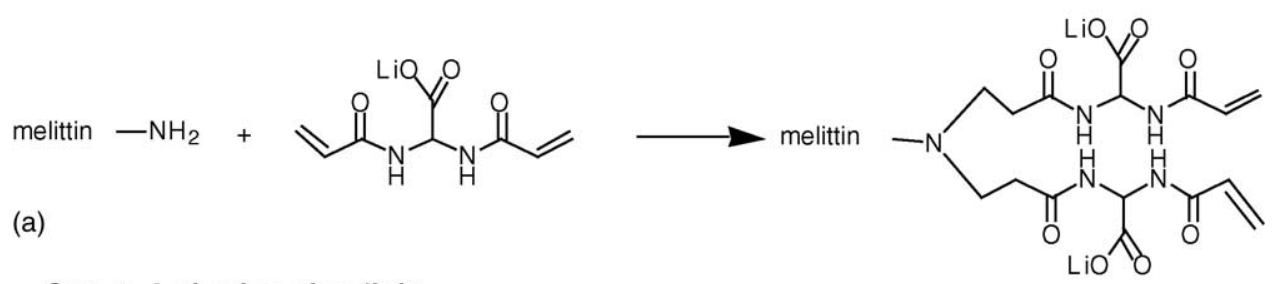

Step 1: Activation of melittin

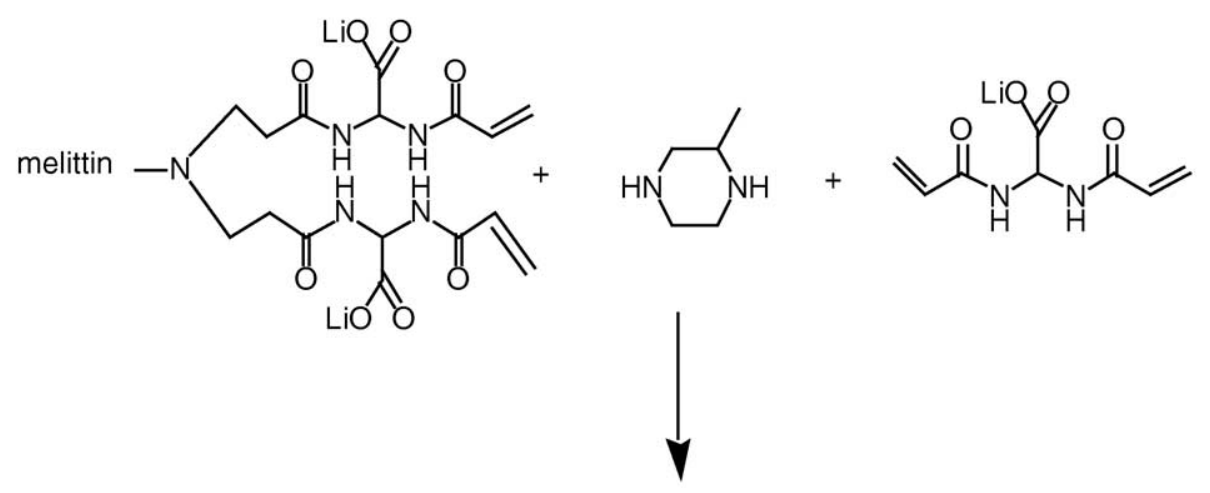

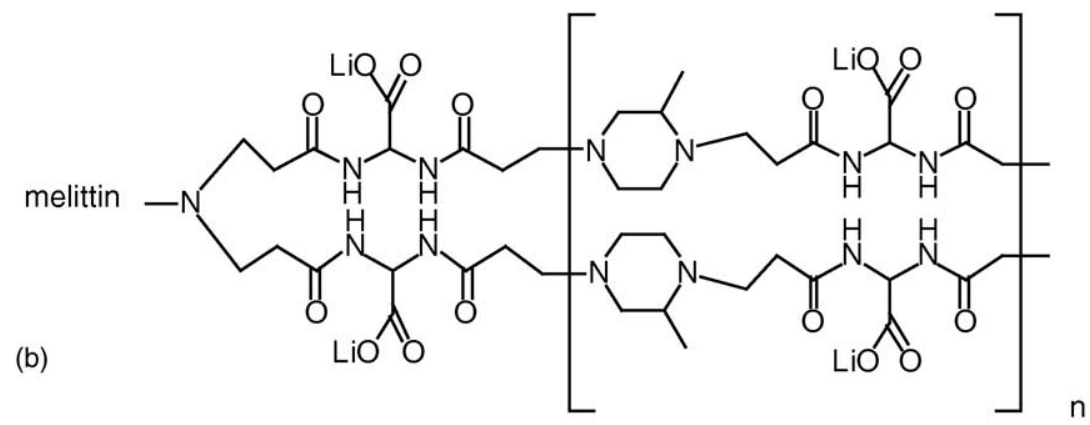

Step 2: Copolymerisation of activated melittin

Scheme 2. Synthesis of the melittin-ISA23-like conjugate.

chromatography (GPC). The MLT content was determined using a BCA protein assay and residual free melittin was assessed by FPLC. GPC was conducted at $30^{\circ} \mathrm{C}$ using Toso-Haas 486 columns. Sample concentration: $10 \mathrm{mg} / \mathrm{ml}$; flow rate: $1 \mathrm{ml} / \mathrm{min}$; detector UV Knauer model: $230 \mathrm{~nm}$; eluent: Tris buffer $\mathrm{pH}$ 8. Poly- $N$-vinylpyrrolidinone (PVP) standards were used to estimate $\mathrm{Mw}, \mathrm{Mn}$ and $\mathrm{Mw} / \mathrm{Mn}$. The BCA assay was conducted as follows. Samples at appropriate dilution and BSA standards $(0-25 \mu \mathrm{g} / \mathrm{ml})$ were prepared in PBS pH 7.4 and $100 \mu$ l aliquots were added to 96-well plate. One hundred microlitres of BCA reagent (50:49:1, v/v/v, MA:MB:copper sulphate) was added to all wells. The plate was incubated at $37^{\circ} \mathrm{C}$ for $30 \mathrm{~min}$ after which absorbance was measured at $560 \mathrm{~nm}$. It should be noted that the PAAs do not give a false positive with the BCA assay.

FPLC was conducted at $20^{\circ} \mathrm{C}$ using a Superdex 75 column (Pharmacia Biotech) connected to an AKTA FPLC (Amersham Pharmacia Biotech). The sample concentration was $3 \mathrm{mg} / \mathrm{ml}$; injection volume: $100 \mu \mathrm{l}$; 
eluent: PBS pH 7.4, 0.1 M, NaCl 0.15 M; detection: $280 \mathrm{~nm}$ and flow rate: $0.5 \mathrm{ml} / \mathrm{min}$. The percentage content of free MLT was assessed by comparison with a calibration obtained using free MLT standard samples $(0-5 \mathrm{mg} / \mathrm{ml})$.

\subsection{Cell culture and evaluation of PAA-MLT cytotoxicity}

B16F10 cells were cultured in RPMI-1640 supplemented with $5 \mathrm{mM}$ L-glutamine and $10 \%(\mathrm{v} / \mathrm{v})$ heat inactivated FBS. The cells were sub-cultured every 4 days at a split ratio of 1:10. Polymer cytotoxicity (PAAs and PAA melittin conjugates) was assessed during the log phase of cell growth using an MTT assay as described previously (Sgouras and Duncan, 1990). Briefly, cells were seeded at a density of $1 \times 10^{4}$ cells/well $24 \mathrm{~h}$ prior to the assay. At the start of the experiment the culture medium was removed and the desired polymer solution $(0-2 \mathrm{mg} / \mathrm{ml}$ in complete medium) was added $(100 \mu \mathrm{l})$. After $67 \mathrm{~h}$ MTT $(20 \mu \mathrm{l}$; $5 \mathrm{mg} / \mathrm{ml}$ in PBS) was added and the plates re-incubated for a further $5 \mathrm{~h}$. The formazan crystals were dissolved in DMSO and the absorbance read at $550 \mathrm{~nm}$ using a microtitre plate reader. The results were expressed as viability (\%) relative to a control containing no polymer.

\subsection{Evaluation of PAA-MLT mediated gelonin delivery}

A method previously described (Pattrick et al., 2001; Lavignac et al., 2004) was used to assess the ability of the PAA-melittin conjugate to deliver gelonin (Stirpe et al., 1980). B16F10 cells were plated as described above. PAAs $(0-2 \mathrm{mg} / \mathrm{ml})$ were then added to cells in the presence or absence of gelonin $(1.4 \mu \mathrm{g} / \mathrm{ml}$, a nontoxic concentration of gelonin alone) and cytotoxicity was determined after $72 \mathrm{~h}$ by MTT assay as described above.

\subsection{Evaluation of PAA-MLT haemolytic activity}

The haemolytic activity of the PAAs was evaluated using a rat red blood cell lysis assay as previously described (Carreno-Gomez and Duncan, 1997). Freshly prepared rat erythrocytes (RBC) were resuspended in cold PBS of the appropriate $\mathrm{pH}$ at a $2 \%$ (w/v) RBC concentration. Solutions of each conjugate $(2 \mathrm{mg} / \mathrm{ml})$ were prepared in PBS at a starting $\mathrm{pH}$ of 5.5, 6.5 and 7.4. These solutions $(100 \mu \mathrm{l})$ were added to $96-$ well plates and the appropriate RBC suspension was added at a $1: 1(\mathrm{v} / \mathrm{v})$ ratio. The plates were incubated for $1 \mathrm{~h}$ at $37^{\circ} \mathrm{C}$. Unlysed erythrocytes were removed by centrifugation $(1000 \times g, 10 \mathrm{~min}$, room temperature) and $100 \mu \mathrm{l}$ of the supernatant was transferred to a new 96-well plate. Absorbance was measured at $550 \mathrm{~nm}$ using a microtitre plate-reader. Haemolysis was expressed as a percentage of the haemoglobin $(\mathrm{Hb})$ release obtained using Triton X-100 (1\%, w/v, Triton $\mathrm{X}-100)$.

\section{Results}

The characteristics of the PAAs prepared in this study are shown in Table 1 . The weight average molecular weight of the ISA1-MLT and ISA23-MLT was 13,370 and $10,870 \mathrm{~g} / \mathrm{mol}$, respectively. MLT content was $19.3 \%(\mathrm{w} / \mathrm{w})$ for ISA1-MLT and $6 \%(\mathrm{w} / \mathrm{w})$ for ISA23-MLT. The theoretical maximum value would be $\sim 20 \%$ (w/w). For both conjugates, free MLT content was $<0.2 \%$ (w/w) as determined by FPLC (Fig. 3). Comparison of the cytotoxicity of the PAA-MLT conjugates with that of the parent polymers showed the conjugates to be more cytotoxic than the respec-

Table 1

Characteristics of synthesised polymers

\begin{tabular}{llccc}
\hline Polymer & $\mathrm{Mw}^{\mathrm{a}}(\mathrm{g} / \mathrm{mol})$ & $\mathrm{Mn}^{\mathrm{a}}(\mathrm{g} / \mathrm{mol})$ & $\mathrm{Mw} / \mathrm{Mn}^{\mathrm{a}}$ & MLT content (wt\%) \\
\hline ISA1 & 12,300 & 6,900 & 1.78 & - \\
ISA1-MLT & 13,400 & 4,200 & 3.21 & 19.3 \\
ISA23 & 50,800 & 28,500 & 1.78 & - \\
ISA23-MLT & 10,900 & 5,300 & 2.05 & 6.0
\end{tabular}

The ratio of melittin (MLT) to the polymer was calculated using a BCA assay.

a The molecular weights characteristics were estimated by GPC using PVP standards. 


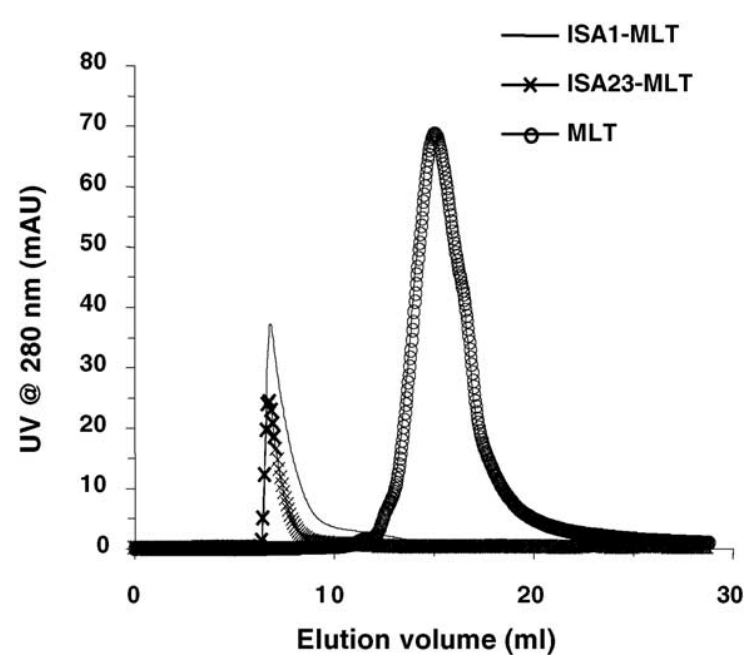

Fig. 3. FPLC of ISA1-MLT ( $3 \mathrm{mg} / \mathrm{ml})$, ISA23-MLT $(3 \mathrm{mg} / \mathrm{ml})$ and free melittin $(5 \mathrm{mg} / \mathrm{ml})$. Eluent: PBS $0.1 \mathrm{M}, \mathrm{NaCl} 0.15 \mathrm{M}$ pH 7.4; detection, $280 \mathrm{~nm}$; flow rate, $0.5 \mathrm{ml} / \mathrm{min}$.

tive parent polymers (Fig. 4a). The $\mathrm{IC}_{50}$ value for ISA1-MLT was $0.04 \mathrm{mg} / \mathrm{ml}$, which represents a 30fold increase in toxicity compared to ISA1. Whereas ISA23 was not toxic towards $\mathrm{B} 16 \mathrm{~F} 10$ cells up to $2 \mathrm{mg} / \mathrm{ml}$, its MLT conjugate had an $\mathrm{IC}_{50}$ value of $0.5 \mathrm{mg} / \mathrm{ml}$. Comparison of conjugate cytotoxicity with free MLT (by expression of the data relative to the equivalent peptide content) (Fig. 4b) indicated that both ISA1-MLT $\left(\mathrm{IC}_{50}=7.8 \mu \mathrm{g} / \mathrm{ml}\right)$ and ISA23-MLT $\left(\mathrm{IC}_{50}=30 \mu \mathrm{g} / \mathrm{ml}\right)$ were significantly less toxic than free $\operatorname{MLT}\left(\mathrm{IC}_{50}=4.5 \mu \mathrm{g} / \mathrm{ml}\right)$. ISA1-MLT was able to deliver gelonin to the cytosol of B16F10 cells with an $\mathrm{IC}_{50}=20 \mu \mathrm{g} / \mathrm{ml}$ for the ISA1-MLT/gelonin combination (Fig. 5a). This corresponds to two-fold increase in toxicity compared to ISA1-MLT alone and a 13-fold increase compared to ISA1-gelonin delivery $\left(\mathrm{IC}_{50}=260 \mu \mathrm{g} / \mathrm{ml}\right)$. In contrast ISA23-MLT, like ISA23, did not deliver gelonin (Fig. 5b).

The haemolytic activity of the PAA-MLT conjugates was evaluated using a red blood cell lysis assay (Fig. 6). At a polymer concentration of $1 \mathrm{mg} / \mathrm{ml}$, both PAA-MLT conjugates were highly haemolytic at all $\mathrm{pHs}$, with $100 \%(\mathrm{Hb})$ release for ISA1-MLT and release for ISA23-MLT. At the lower concentration of $0.05 \mathrm{mg} / \mathrm{ml}$, both conjugates showed $\mathrm{pH}-$ dependent haemolytic activity, although ISA1-MLT was still highly haemolytic ( $\mathrm{Hb}$ release $>50 \%$ at all pHs). At pH 6.5, ISA23-MLT-induced $\mathrm{Hb}$ release was

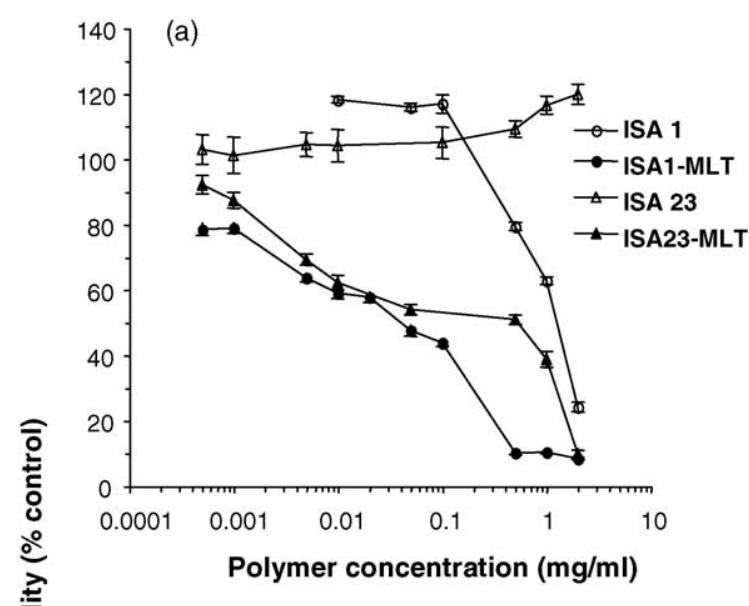

(b)

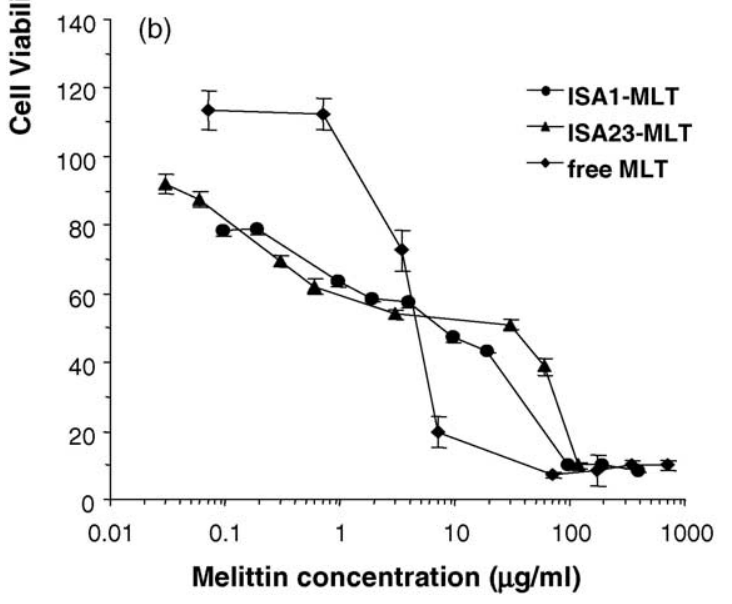

Fig. 4. PAA cytotoxicity towards B16F10 mouse melanoma. Panel (a) shows the relative toxicity of PAAs and PAA-MLT conjugates, panel (b) shows the relative toxicity of MLT and PAA-MLT conjugates. Viability is expressed as \% of control cells incubated in medium alone. Data represent mean \pm S.E.M. where $n=12$.

$20 \%$ and this increased two-fold at $\mathrm{pH}$ 5.5. Moreover, at $\mathrm{pH} 7.4$ the conjugate was not haemolytic, $\mathrm{Hb}$ release was similar to that seen the PBS and dextran controls.

\section{Discussion}

Peptides are being used in gene delivery either to target cells or to increase transfection efficiency (reviewed in Fujii, 1999; Duncan, in press). Influenza virus-derived peptides have shown $\mathrm{pH}$-dependent liposome leakage and haemolytic activities (Wagner et al., 

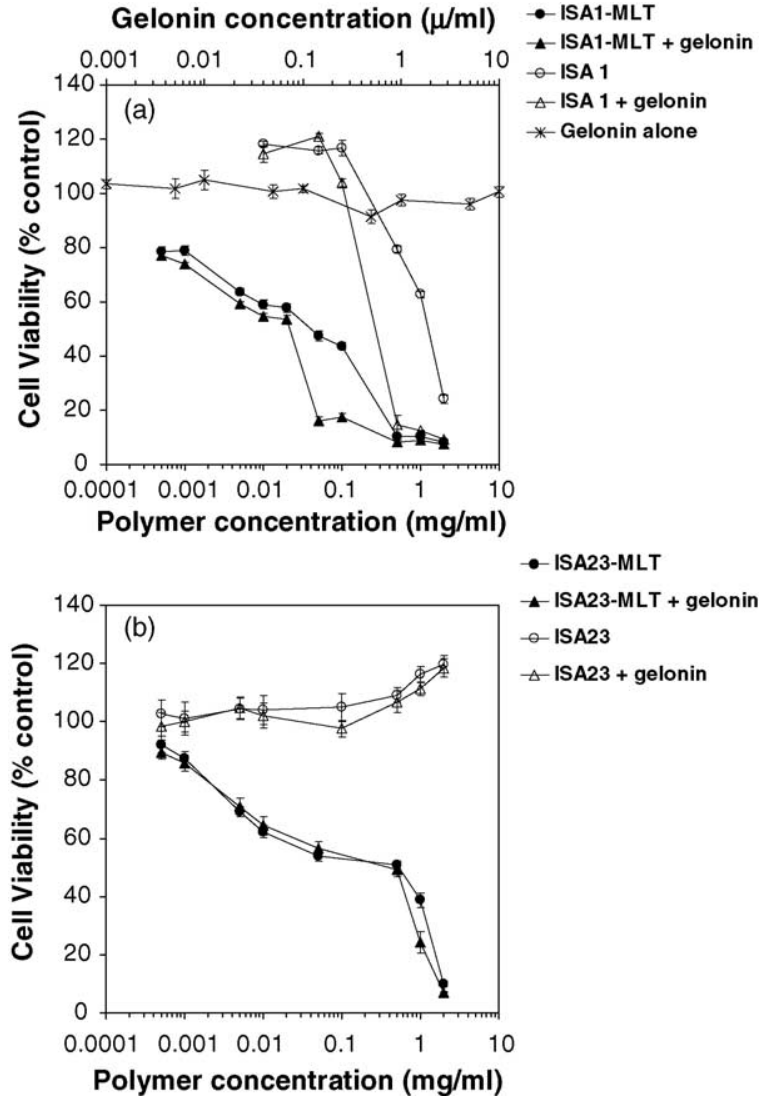

Fig. 5. Ability of PAA-MLT conjugates to deliver gelonin. Panels (a) and (b) show the toxicity of PAA-MLT conjugates when incubated with $\mathrm{B} 16 \mathrm{~F} 10$ cells in the presence and absence of a non-toxic concentration of gelonin $(1.4 \mu \mathrm{g} / \mathrm{ml})$. Data represents mean \pm S.E.M. where $n=12$.

1992). When bound to PLL either ionically or covalently, they have increased transfection efficiency by promoting delivery of DNA to the cytosol (Plank et al., 1994). Melittin has also been used as an endosomolytic agent. A PEI-MLT conjugate was used to form polyplexes that increased gene expression in several cell lines (Ogris et al., 2001). More recently a maleic anhydride derivative of MLT was used to deliver oligonucleotides to the cytosol of Hela cells (Rozema et al., 2003).

Although biologically active PAAs (Ferruti et al., 1973), PAA-based complexing agents (reviewed in Ferruti et al., 2002) and PAA drug conjugates (Ferruti et al., 1999) have been described, relatively few PAA-peptide and PAA-protein conjugates have been synthesised. Ranucci et al. (1995) described a PAA-albumin conjugate prepared using albumin as a macromonomer. That study showed that amino groups present in proteins can react in the same way as low molecular weight amines. A similar method was used to prepare the PAA-MLT conjugates described here. Although melittin contains six amino groups (Lys7, Lys-21, Lys-23, Arg-22, Arg-24 (Fig. 2)) only the $\mathrm{N}$-terminal amino group $\left(\mathrm{p} K_{\mathrm{a}} 7.8\right)$ was expected to be involved in the hydrogen-transfer reaction as it is unprotonated under the reaction conditions. However, due to steric hindrance it was anticipated that reactivity might be low compared with that of the other aminic monomers involved in PAA synthesis. For that reason, the reaction was carried out in two steps as shown in Schemes 1 and 2. In the first step, MLT was left to react for $1 \mathrm{~h}$ with bis-acrylamide to form an "activated trimer" bearing two terminal double bonds that could be used in the final copolymerisation step (Schemes $1 b$ and $2 b$ ). Absence of free MLT was confirmed by FPLC and MLT incorporation was $6-19 \%, w / w$, respectively (Table 1 ). In theory, various routes to MLT conjugation would have been possible using pre-synthesised PAAs. However, it was felt that a macromonomer approach is the best route to a pendant MLT-PAA conjugate.

The results presented here suggest that after conjugation to PAAs, MLT is still able to interact with membranes (Figs. 4 and 6). The mode of action of MLT membrane perturbation is complex. MLT can exhibit 'detergent-like' effects and/or induces membrane pore formation (Bechinger, 1997; Ladokhin and White, 2001; Gomara et al., 2003). These mechanisms have been described using the 'carpet-like model' and the 'barrel-stave model' (Shai, 1999; Schreier et al., 2000). Although it is impossible to speculate as to the mechanism(s) by which the PAA-MLT conjugates interact with the membranes, conjugation to the polymer seems to modify these interactions. Membrane permeabilisation caused by MLT is known to be concentration-dependent (Midoux et al., 1995), with no activity at low concentration. In these studies both PAA-MLT conjugates were more cytotoxic than MLT at concentrations below the $\mathrm{IC}_{50}$ of free MLT (Fig. 4b). In contrast, at concentrations greater the free MLT IC I0 $_{50}$ value, and up to $100 \mu \mathrm{g} / \mathrm{ml}$, both conjugates were less toxic than MLT. This suggests that at low concentration, MLT conjugation to the polymer promotes interaction 


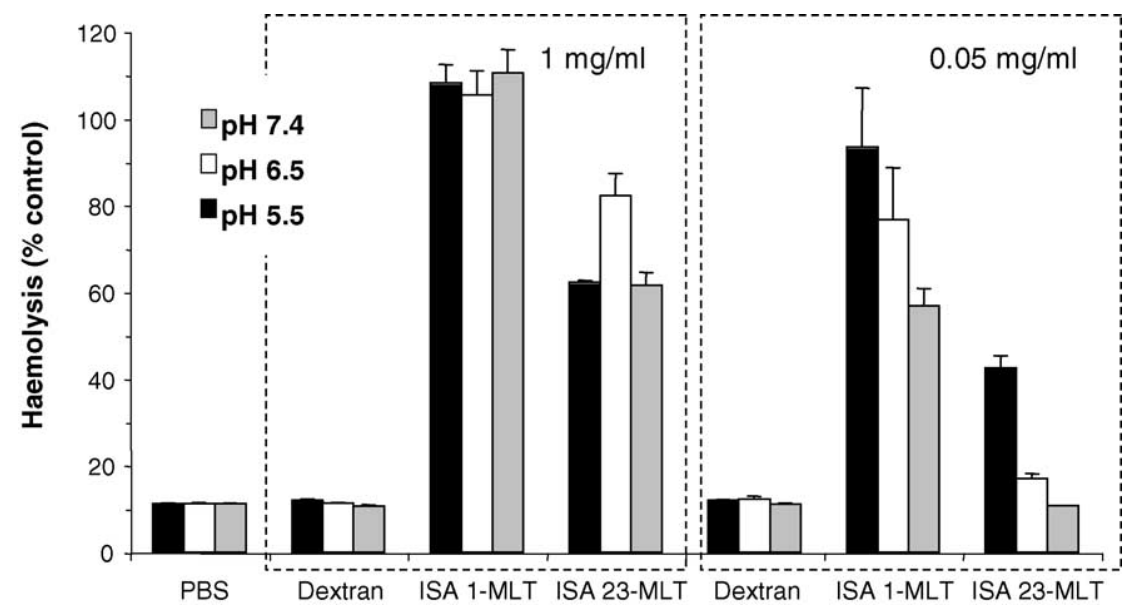

Fig. 6. pH-dependent haemolytic activity of PAA-MLT after $1 \mathrm{~h}$ incubation at $37^{\circ} \mathrm{C}$. Two polymer concentrations were used (either $1 \mathrm{mg} / \mathrm{ml}$ or $0.05 \mathrm{mg} / \mathrm{ml})$. Hb release is expressed as \% of the value obtained by Triton X-100 (1\%, w/v). Data represent mean \pm S.E.M. where $n=12$.

with membranes, perhaps due to the multivalent nature of the construct, whereas at higher concentration activity was lower possibly by polymer hindrance of the formation of melittin tetramers (Dempsey, 1990).

The ability of PAAs to facilitate gelonin-mediated toxicity has been used as an indicator of their endosomolytic potential (Pattrick et al., 2001). The relatively large number of PAA molecules required to facilitate toxin delivery might be due to the low efficiency of membrane breakage or due to differential intracellular trafficking pathway of PAA and toxin when

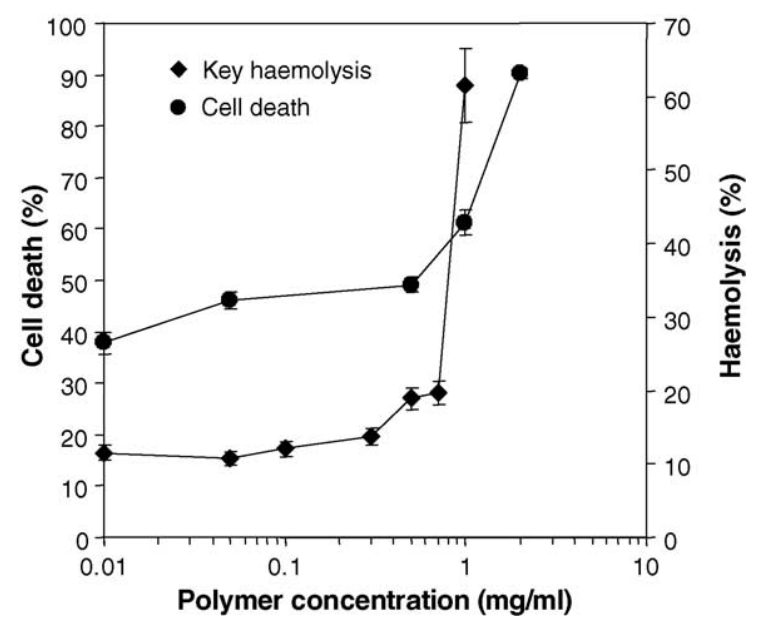

Fig. 7. Correlation between concentration-dependence cell killing and haemolytic activity of ISA23-MLT. Data represent mean \pm S.E.M. where $n=12$. added to the incubation medium as a simple mixture (Pattrick et al., 2001). Whereas ISA1-MLT showed greater ability to deliver gelonin $(\sim 13$-fold $)$ than the parent polymer, neither ISA23-MLT nor ISA23 alone demonstrated gelonin delivery (Fig. 5). Although this is consistent with previous observations involving the ISA23-gelonin combination (Pattrick et al., 2001), it is noteworthy that the ISA1-MLT conjugate has a higher MLT content $(\sim 19 \%, w / w)$ than ISA23-MLT $(\sim 6 \%$, $\mathrm{w} / \mathrm{w})$. These preliminary results suggest that synthesis of a library of PAAs with a range of MLT content would be interesting, to see if ISA23-MLT would deliver gelonin if a higher loading were used.

Previously melittin has been explored as an anticancer agent. A melittin-based recombinant immunotoxin exhibited specific cytotoxicity against human tumour cells (Dunn et al., 1996) and more recently an HPMA copolymer-MLT conjugate showed in vitro toxicity towards B16F10 cells with reduced haemolytic activity (Musila and Duncan, 2001). This prompted consideration of ISA23-MLT as an anticancer polymer therapeutic. The relationship between ISA23-MLT conjugate concentration and both the haemolytic activity and cytotoxicity is shown in Fig. 7. Whereas ISA23-MLT was not haemolytic (compared to the PBS control) up to a concentration of $0.3 \mathrm{mg} / \mathrm{ml}$, it was able to decrease cell viability at concentrations of $0.01-0.3 \mathrm{mg} / \mathrm{ml}$ suggesting that this conjugate could have potential for further development as an anticancer conjugate. 


\section{Conclusions}

Novel ISA1- and ISA23-like MLT conjugates have been prepared. Both conjugates displayed $\mathrm{pH}-$ dependent haemolytic activity and ISA1-MLT also enhanced intracellular delivery of the non-permeant toxin gelonin compared to the parent ISA1 polymer. Whilst ISA23-MLT did not deliver gelonin, its lack of haemolytic activity at $\mathrm{pH} 7.4$, and retention of cytotoxicity, suggests it worthy of further evaluation as an anticancer polymer therapeutic.

\section{Acknowledgement}

We would like to thank BBSRC for supporting this work.

\section{References}

Bechinger, B., 1997. Structure and functions of channel-forming peptides: magainins, cecropins, melittin and alamethicin. J. Memb. Biol. 156, 197-211.

Carreno-Gomez, B., Duncan, R., 1997. Evaluation of the biological properties of soluble chitosan and chitosan microspheres. Int. J. Pharm. 148, 231-240.

Dempsey, C.E., 1990. The actions of melittin on membranes. Biochim. Biophys. Acta 1031, 143-161.

Duncan, R., Ferruti, P., Sgouras, D., Tuboku-Metzger, A., Ranucci, E., Bignotti, F., 1994. A polymer-Triton X-100 conjugate capable of $\mathrm{pH}$-dependent red blood cell lysis: a model system illustrating the possibility of drug delivery within acidic intracellular compartments. J. Drug Target. 2, 341-347.

Duncan, R. Targeting and intracellular delivery of drugs. In: Meyers, R.A. (Ed.), Encyclopaedia of Molecular Cell Biology and Molecular Medicine. WILEY-VCH Verlag, GmbH \& Co. KGaA, Weinheim, Germany, in press.

Dunn, R.D., Weston, K.M., Longhurst, T.J., Lilley, G.G., Rivett, D.E., Hudson, P.J., Raison, R.L., 1996. Antigen binding and cytotoxic properties of a recombinant immunotoxin incorporating the lytic peptide, melittin. Immunotech 2, 229-240.

Ferruti, P., Danusso, F., Franchi, G., Polentarutti, N., Garattini, S., 1973. Effects of a series of new synthetic high polymers on cancer metastases. J. Med. Chem. 16, 497-499.

Ferruti, P., 1985. Poly(amido-amine)s. Macromol. Synth. 9, 25.

Ferruti, P., 1996. Ion chelating polymers for medical applications. In: Salamone, J.C. (Ed.), Polymeric Materials Encyclopedia. CRC Press, Boca Raton, pp. 3334-3359.

Ferruti, P., Ranucci, E., Trotta, F., Gianasi, E., Evagorou, G.E., Wasil, M., Wilson, G., Duncan, R., 1999. Synthesis, characterisation and antitumour activity of platinum(II) complexes of novel functionalised poly(amidoamine)s. Macromol. Chem. Phys. 200, $1644-1654$.
Ferruti, P., Manzoni, S., Richardson, S.C.W., Duncan, R., Pattrick, N.G., Mendichi, R., Casolaro, M., 2000. Amphoteric linear poly(amido-amine)s as endosomolytic polymers: correlation between physicochemical and biological properties. Macromolecules 33, 7793-7800.

Ferruti, P., Marchisio, M.A., Duncan, R., 2002. Poly(amidoamine)s: biomedical applications. Macromol. Rapid Commun. 23, 332-355.

Fujii, G., 1999. To fuse or not to fuse: the effects of electrostatic interactions, hydrophobic forces, and structural amphiphilicity on protein-mediated membrane destabilization. Adv. Drug Del. Rev. 38, 257-277.

Gomara, M., Nir, S., Nieva, J., 2003. Effects of sphingomyelin on melittin pore formation. Biochim. Biophys. Acta 1612, 83-89.

Griffiths, P.C., Paul, A., Khayat, Z., Wan, K.-W., King, S.M., Grillo, I., Schweins, R., Ferruti, P., Franchini, J., Duncan, R., 2004. Understanding the mechanism of action of poly(amidoamine)s as endosomolytic polymers; correlation of physicochemical and biological properties. Biomacromolecules 5, 1422-1427.

Ladokhin, A., White, S., 2001. 'Detergent-like' permeabilization of anionic lipid vesicles by melittin. Biochim. Biophys. Acta 1514, 253-260.

Lavignac, N., Lazenby, M., Foka, P., Malgesini, B., Verpilio, I., Ferruti, P., Duncan, R., 2004. Synthesis and the biological evaluation of the endosomolytic properties of random and block co-polymers of the poly(amidoamine)s ISA1 and ISA23. Macromol. BioSci. 4, 922-929.

Matsumura, Y., Maeda, H., 1986. A new concept for macromolecular therapeutics in cancer chemotherapy: mechanism of tumoritropic accumulation of proteins and the antitumor agent SMANCS. Cancer Res. 46, 6387-6392.

Midoux, P., Mayer, R., Monsigny, M., 1995. Membrane permeabilization by alpha-helical peptides: a flow cytometry study. Biochim. Biophys. Acta 1239, 249-256.

Musila, R., Duncan, R., 2001. Synthesis and Evaluation of HPMA copolymer-melittin as a potential anticancer agent. In vivo studies in the mouse. J. Pharm. Pharmacol. 52, 51.

Ogris, M., Carlisle, R., Bettinger, T., Seymour, L.W., 2001. Melittin enables efficient vesicular escape and enhanced nuclear access of nonviral gene delivery vectors. J. Biol. Chem. 50, 4755047555.

Pattrick, N.G., Richardson, S.C.W., Casolaro, M., Ferruti, P., Duncan, R., 2001. Poly(amidoamine) mediated intracytoplasmic delivery of ricin A-chain and gelonin. J. Cont. Rel. 77, 225-232.

Plank, C., Oberhauser, B., Mechtler, K., Koch, C., Wagner, E., 1994. The influence of endosome-disruptive peptides on gene transfer using synthetic virus-like gene transfer systems. J. Biol. Chem. 17, 12918-12924.

Ranucci, E., Bignotti, F., Paderno, P.L., Ferruti, P., 1995. Modification of albumins by grafting poly(amido amine) chains. Polymer 36, 2989-2994.

Richardson, S., Ferruti, P., Duncan, R., 1999. Poly(amidoamine)s as potential endosomolytic polymers: evaluation in vitro and body distribution in normal and tumour-bearing animals. J. Drug Target. 6, 391-404.

Richardson, S.C.W., Pattrick, N.G., Man, Y.K.S., Ferruti, P., Duncan, R., 2001. Poly(amidoamine)s as potential non-viral vectors: 
ability to form interpolyelectrolyte complexes and to mediate transfection in vitro. Biomacromolecules 2, 1023-1028.

Rozema, D., Ekena, K., Lewis, D., Loomis, A., Wolff, J., 2003. Endosomolysis by masking of a membrane-active agent (EMMA) for cytoplasmic release of macromolecules. Bioconjug. Chem. 14, 51-57.

Schreier, S., Malheiros, S., Paula, E., 2000. Surface active drugs: self-association and interaction with membranes and surfactants. Physicochemical and biological aspects. Biochim. Biophys. Acta 1508, 210-234.

Sgouras, D., Duncan, R., 1990. Methods for the evaluation of biocompatibility of soluble synthetic polymers which have potential for biomedical use. 1. Use of the tetrazolium-based colorimetric assay (MTT) as a preliminary screen for evaluation of in vitro cytotoxicity. J. Mater. Sci.: Mater. Med. 1, 61-68.

Shai, Y., 1999. Mechanism of the binding, insertion and destabilization of phospholipid bilayer membranes by alpha-helical antimicrobial and cell non-selective membrane-lytic peptides. Biochim. Biophys. Acta 1462, 55-70.
Stirpe, F., Olsnes, S., Pihl, A., 1980. Gelonin, a new inhibitor of protein synthesis, nontoxic to intact cells. Isolation, characterisation, and preparation of cytotoxic complexes with concanavalin A. J. Biol. Chem. 14, 6947-6953.

Wagner, E., Plank, C., Zatloukal, K., Cotton, M., Birnstiel, M., 1992. Influenza virus hemaglutinin HA-2 H-terminal fusogenic peptides augment gene transfer by transferrin-poly-L-lysine-DNA complexes: towards a synthetic virus-like gene-transfer vehicle. Proc. Natl. Acad. Sci. U.S.A. 89, 7934-7938.

Wagner, E., 1999. Application of membrane-active peptides for nonviral gene delivery. Adv. Drug Del. Rev. 38, 279289.

Wagner, E., 2004. Strategies to improve DNA polyplexes for in vivo gene transfer: will artificial viruses be the answer? Pharm. Res. $21,8-14$.

Wan, K.-W., Malgesini, B., Verpilio, I., Ferruti, P., Griffiths, P.C., Paul, A., Hann, A.C., Duncan, R., 2004. Poly(amidoamine) salt form affects $\mathrm{pH}$-dependent membrane activity and polymer conformation in solution. Biomacromolecules 5, 1102-1109. 